\section{THE MECHANISM OF THE FIRST SOUND OF THE HEART.}

WHILST every one knows that the action of the heart is accompanied by sounds described as the first and second sounds of the heart, it is a remarkable fact that the mechanism by which the former of these phenomena is produced remains undetermined. It may be said to be almost universally accepted that the second sound is the result of the sudden tension of the semilunar valves, caused by the resistance which they offer to reflux of blood from the great vessels into the ventricles on the cessation of the systole. The difficulties which exist are connected with the first sound, and they result mainly from the fact that a number of events occur simultaneously with the systole of the ventricles and with the sound. Two of the most striking of these events, namely, the closure of the auriculo-ventricular valves and the muscular contraction of the walls, are regarded by many authorities as the source of the first sound. Sir Richard Quain in a paper recently read before the Royal Society has given a very graphic account of certain im portant investigations which lead him to the conclusion that neither of these explanations is correct, and which at the same time enable him to indicate what he believes to be the real explanation of the first sound of the heart.

In the first place, the author of this communication brings forward strong evidence to show that the action of the auriculo-ventricular valves is not the source of the first sound of the heart. This action consists in the simple apposition of the laminæ of these valves and the closure of the orifices by the musculi papillares and chordæ tendineæ, and affords no such tensive force as would suffice to produce the loud and characteristic sound which accompanies systole. More positive evidence is derived from the fact that the first sound can be heard independently of the existence and action of mitral and tricuspid valves in some of the lower animals, especially reptiles such as the python, which the author carefully auscultated in the Zoological Gardens, or when the valves are rudimentary, as in the kangaroo. The mitral murmurs familiar to physicians are, of course, formed at the mitral valve during systole; but they have no relation except in time with the first sound ; they are merely accidental complications which occur at the moment of ventricular contraction, and the healthy first sound may be heard along with and independently of them.

In the second place, Sir Richard Quain shows that the muscular contraction of the walls of the heart during systole is not the source of the first sound of the heart. It is true that muscular contraction is accompanied by a sound, but this possesses neither the loudness nor the characteristic tone of the first cardiac sound. In opposition to the old experiments of Ludwig and Dogiel, which appear to show that after cutting off altogether the supply of blood from the cavities, one can still hear a systolic sound, the author puts the experimenis of Prof. Holford, who made out that the sounds are heard or cease, respectively, according as blood is or is not admitted into the chambers. The classical observation of Stokes of Dublin that the first sound of the heart gradually disappears in the course of typhus fever, does not prove that muscular contraction causes the first sound, but that the impulse of the heart is so feeble that it is unable to produce the sound at the semilunar valves. The correctness of this view is confirmed by the fact recorded by Stokes, that the last point where the sound disappears in typhus is over these valves, whilst it is at the same point that it first returns. Further, Dr. Alexander Morison, working for Sir Richard Quain, found that in the bloodless heart of a recently killed turtle no sound could be heard during contraction sufficient to expel blood from the cavity. These facts and observations are, in the author's NO. 1459, VOL. 56] opinion, sufficient to prove that the contractile action of the muscles of the heart are not capable of producing the first sound.

After this destructive criticism, Sir Richard Quain proceeds to consider a third event which occurs during systole, namely, the propulsion of the blood contained in the ventricles into the pulmonary artery and aorta; and herein he finds the agency by which the sound in question is produced. He maintains that the first sound of the heart is caused by the impact of the blood driven by the action of the muscular walls of the ventricles against the block produced by the columns of blood in the pulmonary artery and aorta, which press upon the semilunar valves. Dr. Pettigrew has shown that the column of blood projected from the heart into the aorta (to take the left side only as illustration), is formed by the union of three columns with a spiral motion which is the result of the spiral arrangement of the musculi papillares and of the fibres of the walls of the ventricles, as well as of the spiral shape of the left ventricular cavity itself. By this rifle motion the blood is directed against the segments of the semilunar valves, which are hastily thrown apart, the spiral current being continued for some distance within the aorta. This beautiful rifle mechanism is constructed to give precision to the direction of the moving body against a given point, and to secure also velocity and force. In fact, we have here in nature the mechanism of the modern rifle. A resistance to the stream of blood from the ventricle is offered by the block formed by the column of blood resting on the aortic valves, wedged, and as it were screwed tightly, into each other. Whatever may be the absolute value of the propelling force of the left ventricle, authorities are agreed that the driving power and the resistance are to each other in the proportion of about four to three, the really important point being the relation they bear to each other. Now in this motion and in this resistance we have all the elements for the production of sound, inasmuch as sound is a phenomenon resulting from resisted motion. A sound being produced, we ask, What is it? and the reply must be: The first sound of the heart, the cause of which we seek. This explanation was first suggested to Sir Richard Quain's mind many years ago by a case of disease, in which the aortic valves were completely broken down and had become inadequate to their function. A murmur of such intensity was produced that it was audible three inches from the walls of the chest without a stethoscope. Over the femoral artery, however, there was no murmur, but a sound precisely resembling the first sound, caused by the motion of blood in the artery which received the full force of the ventricular contraction, the valves being clestroyed. His attention was thereby directed to the natural obstruction offered by the aortic valves in health to the blood leaving the ventricle. Many observations have been made on the circulation in the femoral artery under like circumstances by continental physicians, but these have had reference to diagnosis only, not to the cause of the first sound of the heart in health.

An objection might be offered to this explanation of the first sound of the heart, that it is heard more distinctly at the apex of the organ, a point removed from the seat of the valves. The observation is correct, and the explanation of it is simple. The muscular walls of the heart are connected with the fibroid ring intimately associated with the semi-lunar valves. The sound produced at these valves is communicated to the apex of the heart through the fibroid ring and the muscular walls, which at the moment of systole are tense and firm. The sound thus conducted reaches that portion of the heart which is uncovered, and which is in contact with the walls of the chest. But, on the other hand, when opportunity offers, it has been found that the sound in question is heard over the aortic valves more distinctly than in any other 
situation. A remarkable case of this kind has been related by M. Cruveilhier, who was invited to see an infant just born presenting a complete case of ectopia of the heart. He says : "On examining the heart thus exposed, both sounds were distinctly heard over the base, and not at the apex."

Lastly, the author has submitted the problem to the test of experiment, and finds that sounds resembling the first and second sounds of the heart can be produced artificially in accordance with his view. A sheep's heart is carefully prepared, and fitted with gutta-percha tubes for inlet and outlet, respectively, of water. If the ventricle be filled from the former, fitted into the left auricle, the water passes into the ventricle, and thence into the aorta, and finally rests upon and closes the aortic valves. If the ventricle be now compressed rhythmically in imitation of systole, and allowed to relax in imitation of diastole, a sound closely resembling the first sound of the heart is produced when the water is propelled from the ventricle into the tube fitted into the aorta; and another sound closely resembling the second sound of the heart is produced when the sigmoid valves close under the superincumbent weight of water in the aortic tube. As the fluid rises in the aortic tube, which is made three feet long, the pressure on the valves increases and the sound becomes more marked; when the fluid, on the other hand, diminishes, the sound becomes less distinct. The terminal piece of small diameter of a binaural stethoscope gently placed over the aorta at its commencement is most suitable for observing the cardiac sounds in this experiment.

It thus appears that the sounds of the heart are both produced at the same point-that is, at the semi-lunar valves; and each of them by its own single and simple agency.

Sir Richard Quain was moved to undertake and continue this inquiry by a desire to obtain a solution of what seemed to be an insoluble problem, and also by a belief that a correct explanation of the first sound of the heart would be of practical value in the study of the clinical phenomena of diseases of this organ. If the explanation given by him is so different from that hitherto accepted as to be calculated to create difficulties in the diagnosis of valvular diseases of the heart, closer consideration will show that this is not the case, but that, like all accurate knowledge, it simplifies and does not confuse. It affords an explanation of the relations of certain morbid phenomena which are at present unintelligible, such, for example, as that a systolic murmur may be heard at the apex, whilst the first sound is audible at the base free from murmur ; and it will serve to encourage a closer study of the relation between muscular contraction of the walls of the heart and the tension of the vessels of the system.

\section{THE DIVINING ROD. ${ }^{1}$}

$\mathrm{T} T$ is certainly advisable to inquire into the foundation of all popular beliefs. In some cases popular feeling, or superstition-call it what you will-has undoubtedly led to the discovery of truths not at first understood or accepted by men of science. As, for instance, the danger in the proximity of the barberryplant to crops of corn; a danger well known, though unexplained until the microscope was used to trace out the life-history of the minute organism which causes the mischief. On the other hand, careful and unprejudiced inquiry may prove the utter baselessness of some universally accepted belief. We have an instance of this in

1 "On the So-called Divining Rod, or Virgula Divina: a scientific and histor ical research as to the existence and practical value of a peculia human faculty, unrecognised by science, locally known as dowsing." B Prof. W. F. Barrett. (Proc. Soc. Psyclical Revecerch, part xxxii., vol. xiii July; 1897.)

$$
\text { NO. } 1459,10: 56]
$$

the statistical inquiry into the connection between the changes of the moon and of the weather. Such a connection is apparently taken for granted by every sailor and farmer; yet a careful analysis of the records shows that the belief is entirely groundless. We are inclined, therefore, to welcome a scientific investigation into the common use of the divining rod for the purpose of finding water or metallic ores.

Turning to the paper of 280 pages which forms the text of this article, we must confess to a feeling of considerable disappointment at the way in which the subject has been treated. What are the points at issue? And what should be the method adopted? Before entering into these questions it may be well to explain in a few words what is the "divining" or "dowsing" about which so much has been written. Here we can recommend Prof. Barrett's paper. He gives a lucid account of the process, clearly distinguishing between the instruments used, which he explains are evidently of no importance whatever, and the physical or mental state of the operator, which is the matter of real moment.

"Divining" or "dowsing" is a method of finding hidden springs or ores by the employment of persons supposed to possess a peculiar faculty not common to mankind in general. This faculty takes the form of a special sensitiveness which causes a forked hazel-twig, or other pointer, held in the hands, to point downward, or upward, when the operator is vertically over the thing sought for. The pointer is a mere "autoscope ;" for one dowser used a watch-spring, another a German sausage, and others go with nothing in the hands. The twitching of the rod is, as Prof. Barrett points out, a mere indication of a nuscular disturbance, not otherwise very obvious. In the search for water the usual method of divining is for the operator to walk across the ground, rod in hand, stopping at points where involuntary movements cause the rod to turn. At these spots he considers that water is to be found, and he will often go so far as to state the amount that a well sunk there will yield, and the depth at which the spring will be struck. We refer specially to the discovery of water; but the same method is used for the discovery of ores, and sometimes for the tracking of criminals, the feeling responding only, so it is said, to the presence of the particular object for which search is being made.

Two hundred pages of the paper before us are devoted to an "Examination of Evidence," or rather to records of the employment of diviners for the discovery of hidden springs. To this section we will now turn. It is obviously impossible within the limits of this article to analyse the mass of evidence. The difficulty of obtaining trustworthy information as to depth of wells, level of springs, yield of water and other circumstances is very great. Even where no personal feeling enters into the question, the details supplied need the most careful sifting. All we can here do is to take some one district, and see how far Prof. Barrett's records correspond with memoranda of our own, made in the course of a geological examination of the same area. Our notes were taken simply for the purpose of obtaining details of the strata, not to prove or disprove any theory.

Two wells are mentioned as sunk in the Isle of Wight under the advice of a diviner, both counting as successes. As to the first, at Arreton, we are only given the diviner's own uncorroborated account, and not knowing the exact site of his well it is impossible to form an opinion about it. At the other place mentioned, a house called Woodside, at Wootton, near Ryde, two wells had been sunk, under whose advice we know not, in the Oligocene clays, and, of course, they yielded no water. The diviner afterwards selected a site a few yards further south, on the edge of the sheet of plateau gravel which supplies water to all the farms and houses over its area. It did not need a cliviner to give this advice; any cottager 